\title{
Marked widespread atrophy of the cerebral cortex and brainstem in sporadic amyotrophic lateral sclerosis in a totally locked-in state
}

\author{
Yoko Warabi, Kentaro Hayashi, Masahiro Nagao, Toshio Shimizu
}

Department of Neurology, Tokyo Metropolitan Neurological Hospital, Fuchu, Tokyo, Japan

\section{Correspondence to} Dr Yoko Warabi, youko_warabi@tmhp.jp

Accepted 26 January 2017
CrossMark

To cite: Warabi Y Hayashi K, Nagao M, et al. BMJ Case Rep Published online: [please include Day Month Year] doi:10.1136/ bcr-2016-218952

\section{DESCRIPTION}

A man aged 42 years presented with progressive muscle weakness and fasciculation in his legs. $\mathrm{He}$ was diagnosed with sporadic amyotrophic lateral sclerosis (ALS) based on clinical and electrophysiological upper and lower motor neuron dysfunction. He presented no obvious cognitive or behavioural impairment indicative of frontotemporal dementia (FTD), although detailed cognitive tests were not performed. When he was 43 years old, he presented with tetraplegia and respiratory failure without extraocular muscle impairment and received a tracheostomy with invasive ventilation (TIV). His first brain MRI at age 43 years showed signs of upper motor neuronal degeneration and global discrete cortical atrophy (figure 1). During the ensuing years, he communicated with others using extraocular movements and did not exhibit any symptoms of obvious dementia. When he was 46 years old, his extraocular muscles became nonfunctional. He lost his voluntary motor function and communication ability entirely, falling into the so-called 'totally locked-in state (TLS)'. ${ }^{1}$ A brain MRI at age 47 years, 1 year after TLS onset, showed severe atrophy of the bilateral precentral gyrus (figure 2). The bilateral frontal lobes, anterior temporal lobes, putamen and tegmentum of the mesencephalon also showed progression of atrophy (figure 2). A brain MRI at age 53 years, 10 years after the TIV and 7 years after TLS onset, showed progressive and marked atrophy in the frontal, temporal and parietal cortical lobes, basal ganglia and brainstem (figure 3 ). In contrast, his occipital lobe was relatively well preserved.

Sporadic ALS, which usually displays TDP-43 pathology, can progress to a very advanced stage with complete quadriplegia and ophthalmoplegia resulting in TLS. TLS is observed in $11.4 \%$ of ALS patients on TIV. ${ }^{1}$ ALS patients in a TLS may exhibit severe, widespread involvement of the cerebral cortex and brainstem. ${ }^{2}$ This study is the first to demonstrate the chronological changes in sporadic ALS in a TLS using MRI images.

ALS and FTD share the pathological manifestations of frontotemporal lobar degeneration (FTLD). ${ }^{3}$ However, FTD is a form of cortical dementia which comprises three prototypical clinical FTLD syndromes, including FTD, progressive

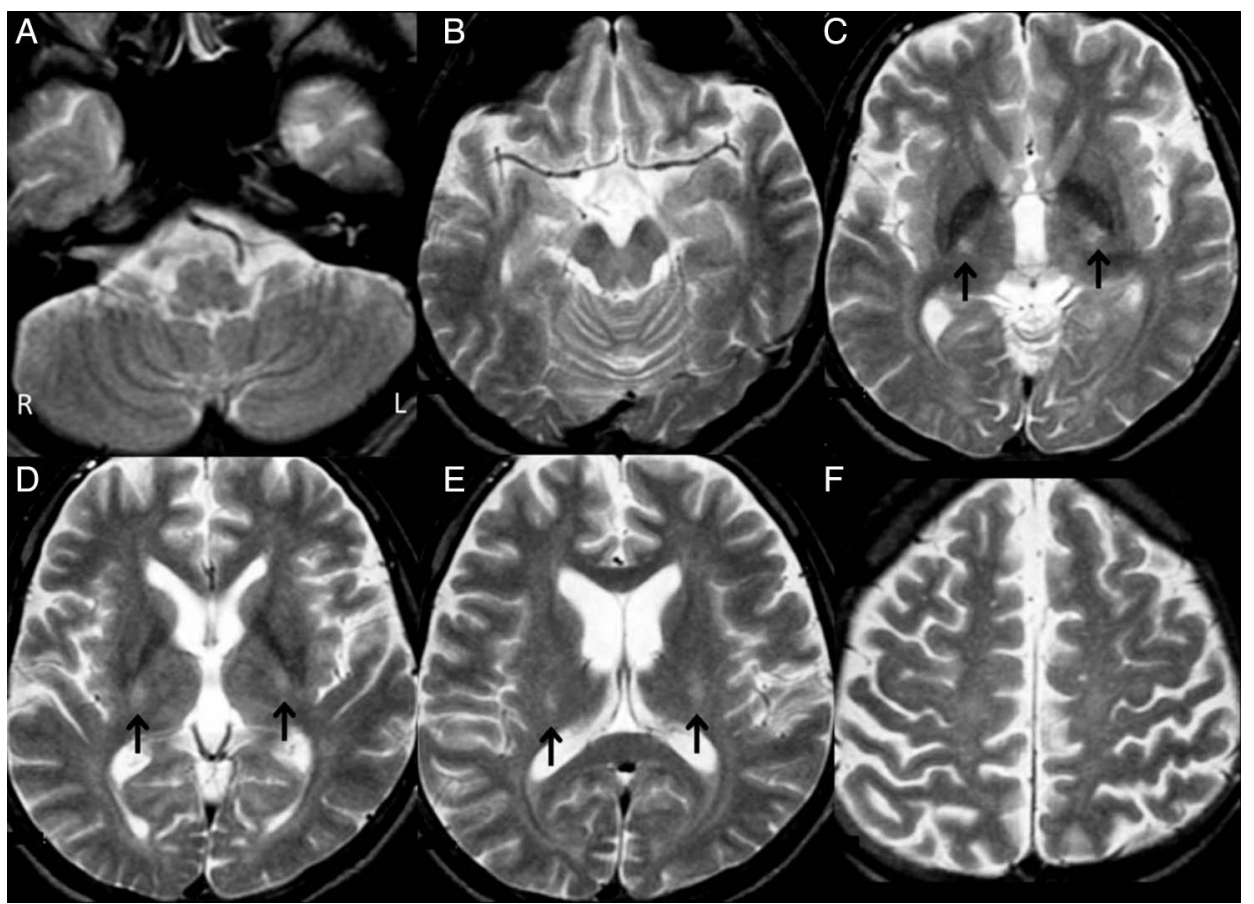

Figure 1 Signs of upper motor neuronal degeneration seen on patient's first MR scan at age 43 years old, just before tracheostomy with invasive ventilation was introduced. (A-F) Axial T2-weighted spin-echo images demonstrated abnormal, bilateral, hyperintense signals along the corticospinal tracts (arrows) consistent with upper motor neuronal degeneration in amyotrophic lateral sclerosis. Global discrete cortical atrophy is also seen. 


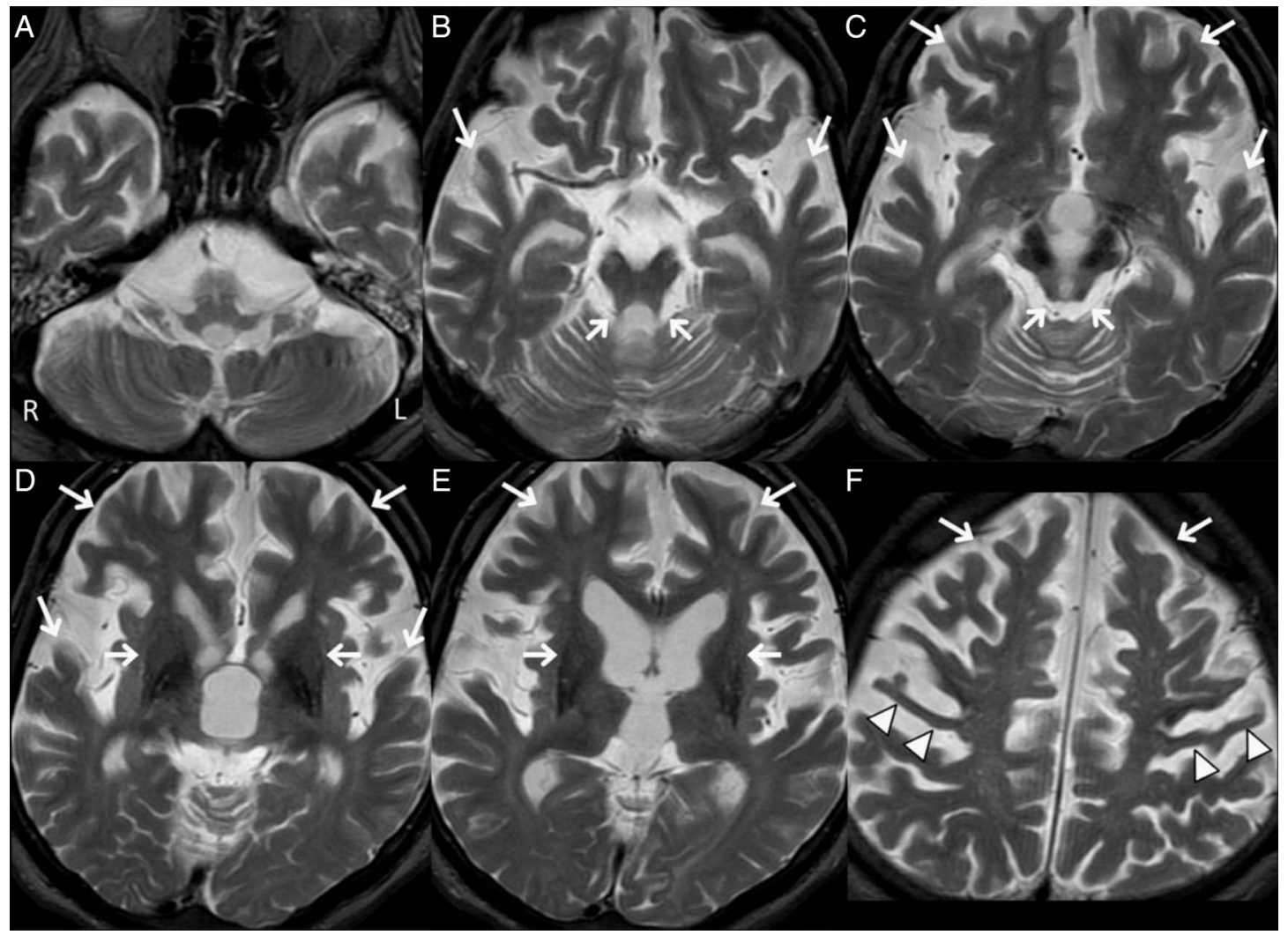

Figure 2 Progressive brain atrophy visualised on MR scan at 47 years old, 1 year after totally locked-in state onset. (A-F) Axial T2-weighted fast spin-echo images demonstrated severe atrophy, particularly of the bilateral frontal lobes, anterior temporal lobes, putamen and tegmentum of the mesencephalon (arrows). (F) Bilateral precentral gyrus also showed severe atrophy (arrowheads).

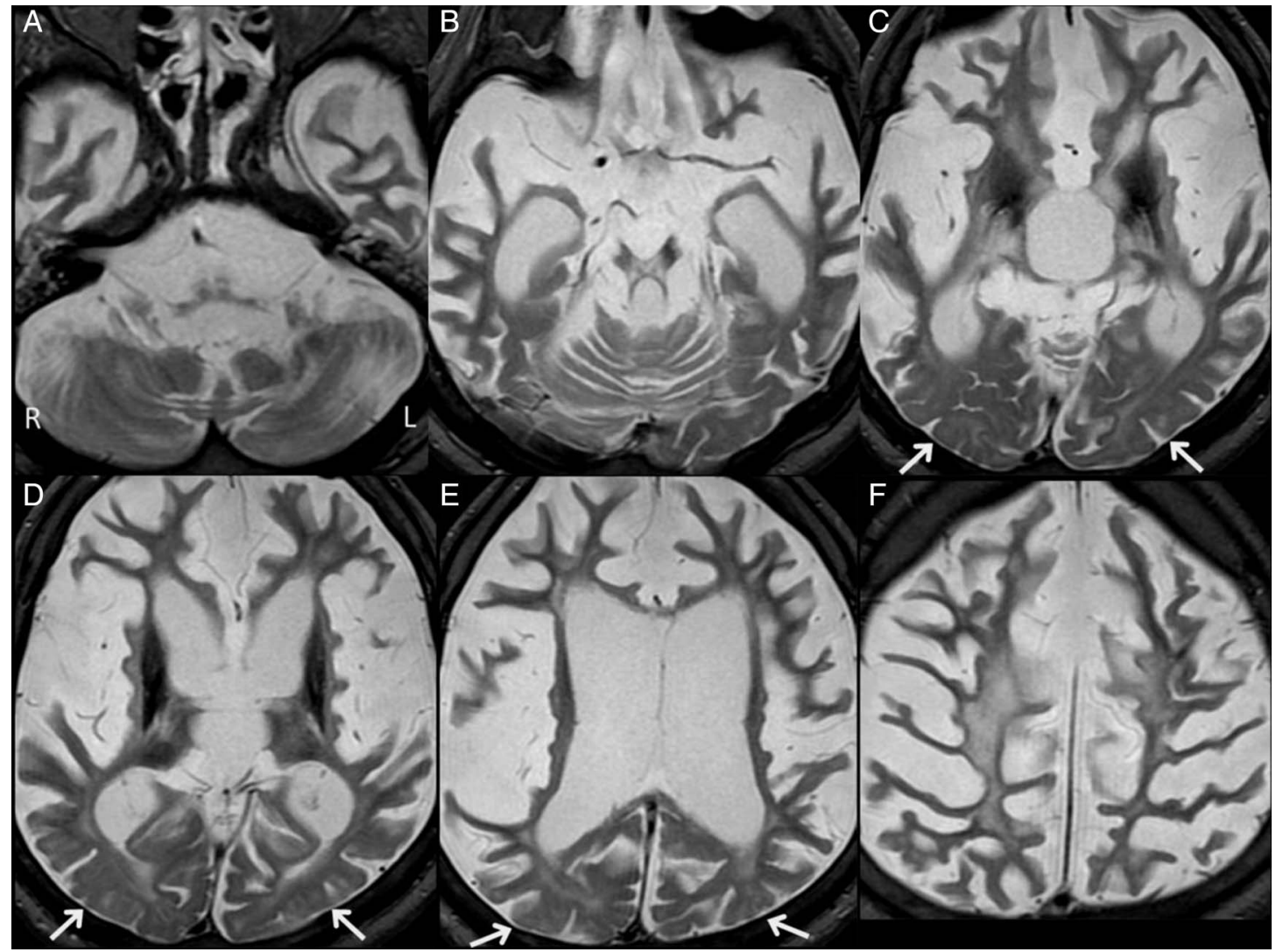

Figure 3 Severely progressive brain atrophy visualised on MR scan at 53 years old, 10 years after the start of tracheostomy with invasive ventilation and 7 years after totally locked-in state onset. (A-F) Axial T2-weighted spin-echo images demonstrated marked atrophy of the frontal, temporal and parietal cortical lobes, basal ganglia and brainstem. (C-E) In contrast, the occipital lobe was relatively well preserved (arrows). 
non-fluent aphasia and semantic dementia. ${ }^{4}$ Few FTD patients show upper or lower motor neuron dysfunction even if their clinical course is protracted. Sporadic ALS with definite upper and lower motor neuron dysfunction but without symptoms of FTD in the presence of severe, widespread, progressive cortical atrophy as seen in our case has hitherto never been documented. This case indicates that some instances of ALS may exhibit severe frontotemporal lobe atrophy on MRI similar to that seen in FTD cases during a prolonged TLS state for reasons as yet unknown.

\section{Learning points}

- This was the first study to use MRI to visualise chronological changes in sporadic amyotrophic lateral sclerosis (ALS) in a totally locked-in state (TLS) consisting in the marked atrophy of large areas of the cortical lobe, a finding which may reflect the clinical manifestations of frontotemporal lobar degeneration pathology.

- The relatively good preservation of the visual cortex might be an advantage in the future development of braincomputer interfaces enabling ALS patients in a TLS to communicate.
Our patient showed relatively good preservation of the occipital lobe on MRI, a finding consistent with those of previous pathological studies of ALS resulting in TLS showing good preservation of the visual pathway. ${ }^{5}$ Preservation of the visual pathway including the visual cortex might be an advantage in the future development of brain-computer interfaces enabling ALS patients in a TLS to communicate.

Contributors The patient's care was overseen by YW, KH, MN and TS. The article was written by YW and TS. KH and MN contributed to critical revision of the article.

Competing interests None declared.

Patient consent Obtained.

Provenance and peer review Not commissioned; externally peer reviewed.

\section{REFERENCES}

1 Hayashi H, Oppenheimer EA. ALS patients on TPPV: totally locked-in state, neurologic findings and ethical implications. Neurology 2003;61:135-7.

2 Kato S, Hayashi H, Yagishita A. Involvement of the frontotemporal lobe and limbic system in amyotrophic lateral sclerosis: as assessed by serial computed tomography and magnetic resonance imaging. J Neuro/ Sci 1993;116:52-8.

3 Chang JL, Lomen-Hoerth C, Murphy J, et al. A voxel-based morphometry study of patterns of brain atrophy in ALS and ALS/FTLD. Neurology 2005:65:75-80.

4 Neary D, Snowden JS, Gustafson L, et al. Frontotemporal lobar degeneration: a consensus on clinical diagnostic criteria. Neurology 1998;51:1546-54.

5 Oyanagi K, Mochizuki Y, Nakayama Y, et al. Marked preservation of the visual and olfactory pathways in ALS patients in a totally locked-in state. Clin Neuropathol 2015;34:267-74

Copyright 2017 BMJ Publishing Group. All rights reserved. For permission to reuse any of this content visit http://group.bmj.com/group/rights-licensing/permissions.

BMJ Case Report Fellows may re-use this article for personal use and teaching without any further permission.

Become a Fellow of BMJ Case Reports today and you can:

- Submit as many cases as you like

- Enjoy fast sympathetic peer review and rapid publication of accepted articles

- Access all the published articles

- Re-use any of the published material for personal use and teaching without further permission

For information on Institutional Fellowships contact consortiasales@bmjgroup.com

Visit casereports.bmj.com for more articles like this and to become a Fellow 